\title{
Strategic Knowledge Management as a Driver for Organizational Excellence: A Case Study of Saudi Airlines
}

\author{
Osama S. Islam ${ }^{1}$ \\ ${ }^{1}$ King Abdulaziz University/ Faculty of Computing and Information Technology, Jeddah, Saudi Arabia \\ Email:1 oislam@stu.kau.edu.sa \\ Mohammed Ashi ${ }^{2}$, Fahad M. Reda ${ }^{3}$ and Dr. Aasim Zafar ${ }^{4}$ \\ ${ }^{2,3}$ King Abdulaziz University/ Faculty of Computing and Information Technology, Jeddah, Saudi Arabia. \\ ${ }^{4}$ Aligarh Muslim University/ Department of Computer Science, Aligarh, India \\ Email: ${ }^{2}$ mashi0004@ stu.kau.edu.sa, ${ }^{3}$ fmasood@ stu.kau.edu.sa, ${ }^{4}$ aasimzafar@ gmail.com
}

\begin{abstract}
Purpose - Achieving organizational excellence requires high-levels of commitment and coordination of multiple dimensions throughout an organization. One dimension that most organizational excellence frameworks highlight is the necessity of having a comprehensive learning system, which focuses on knowledge and training. Therefore, a proper understanding of knowledge management is important to identify the factors that drive the achievement of high organizational performance and excellence.
\end{abstract}

Design/methodology/approach - A case study approach has been used, which utilized in-depth interviews with key personnel to obtain valuable insights into the use of strategic knowledge management to drive operational excellence. While the survey was conducted to assist in analyzing certain perspectives related to knowledge management within the organization.

Findings - The main findings highlight how the emerging enterprise social network systems have played a major role in institutionalizing collaboration and corporate socializing within the organization, which are both important factors for strategic knowledge management to be successful. Based on the study, a framework has been proposed to assist in the successful implementation of strategic knowledge management for the achievement of organizational excellence.

Research limitations/implications - Due to the research approach used some of the findings may include varying degrees of bias in the responses obtained. In addition, due to the lack of time available the proposed framework was not evaluated.

Originality/value - Investigating the link and relationship between strategic knowledge management and organizational performance that lead to higher levels of organizational excellence.

Index Terms - Knowledge Management, Organizational Performance, Information Systems, Strategy.

\section{INTRODUCTION}

Organizations operating in today's global and competitive environments are constantly faced with pressures to improve their operations to provide high quality output to their stakeholders. Thus, organizations have developed strategic capabilities that combine knowledge, skills and technologies to achieve organizational excellence while sustaining their competitive advantages in their respective markets. Various organizational excellence models have been developed by several accreditation bodies, such as the Malcolm Baldrige National Quality Award (MBNQA) and the European Foundation for Quality Management (EFQM) (ASQ, 2016), to assess where an organization is and what needs to be improved to increase their excellence levels. However, the general concept that these models try to determine is that organizations have outstanding operations that continuously deliver excellent results. In addition, these models include a range of areas that define the attributes of organizational excellence.

In recent years, more focus has been placed on knowledge by organizations' top management as they try to identify the complete lifecycle of knowledge (e.g. creation, transfer, retention, and utilization) and best approaches to managing it and creating competitive advantages with it. However, implementing such approaches can be difficult if managers within such organizations are not able to properly understand what knowledge management (KM) is from both a theoretical and practical perspectives. Therefore, an understanding of knowledge flows and theoretical models can help managers to cope with the complexity of knowledge management and can offer some suggestions for practical applications that lead to improvements in organizational performance.

At the same time, to be able to deliver expected excellence levels clear performance objectives must be defined that guide knowledge management activities using a strategy that is based on the organization's overall 
strategy, which clarifies where they are headed, what their short and long term targets are, and the associated action plans. A knowledge management strategy provides an implementation plan, which facilitates enhanced deliverables that leverage the cumulative knowledge of an organization and its members.

The paper attempts to investigate the issues that organizations face when striving to achieve organizational excellence by implementing strategic knowledge management (SKM) and proposes a solution that addresses these issues with a comprehensive and effective knowledge management strategy. In addition, the paper aims to investigate the potential that strategic knowledge management may have as a driver for organizational excellence, through a case study of Saudi Airlines.

However, an overview of knowledge management with its main models and cycles is important to understand first before a proper analysis of its effects on organizational excellence is done. Strategic knowledge management will require the linkage between critical success factors with knowledge enablers that increase the rate of success and levels of achieving organizational excellence.

The remaining parts of the paper is structured with section 2 and 3 providing a brief overview of organizational excellence and knowledge management to provide understanding of the related concepts. Section 4 then examines relevant literature on cycles and models related to knowledge and knowledge management, in addition to highlighting key associated technologies. Section 5 then discusses the related factors that lead to developing effective strategic knowledge management. Section 6 then presents the case study findings, while section 7 analyzes and discusses them and section 8 presents the proposed SKM implementation framework. Then finally, section 9 discusses main recommendations and conclusions reached based on the research findings.

\section{ORgANIZATIONAL EXCELLENCE}

From a general perspective, organizational excellence refers to the focus of an organization to establish a standard set of organizational elements that together deliver outstanding results. These organizational elements have been defined by several models, covering concepts such as, leadership process management, customer centric focus, people, and strategy (ASQ, 2016).

In addition, as indicated by Ringrose (2013) most organizations that adapt such models outperform their competitor in their respective industries. However, Ringrose also highlighted that most of the well-known organizational excellence models include knowledge management as a unique area of focus. While a study by Heisig, et al. (2016) looked at the relationship between knowledge management and business performance to identify key areas of future research. Their key findings indicated the importance of knowledge management in supporting innovation performance and competitive advantage.
Further, Harrington (2006) discussed five pillars that must be managed together to achieve organizational excellence. These pillars are process, project, change, knowledge and resource. His key points include the need for having a knowledge management system that is designed around the organization's key competencies and the need for a collaborative environment that supports knowledge management and excellence.

\section{KNOWLEDGE MANAGEMENT}

Knowledge management as a topic has taken the attention of both the commercial and academic communities, who view knowledge as a key resource for gaining competitive advantage especially in today's knowledge-based economy (Martensson, 2000).

Per (Earl, 1997), knowledge is considered an essential strategic element and economic asset of an organization and is present as a foundation for all functions of the enterprise (Wiig, 1993). While Boisot (1998) views knowledge as a key facilitator to the development and enhancement of products and services.

Argote and Ingram (2000) proposed the idea that effective knowledge processing resembles the grounds for competitive advantage in all kinds of businesses and is crucial to the existence of an organization.

In addition, organizations are becoming more aware that knowledge as a resource is instrumental to the development of their operations. Combined with information systems and technologies, knowledge becomes a critical success factor for the achievement of strategic objectives. Therefore, knowledge needs to be carefully managed to sustain creative and productive practices within an organization that assist in the full lifecycle of knowledge management.

Knowledge management can also be viewed as the intentional and structured approach to organize and coordinate the creation and usage of helpful information and knowledge produced by its members that add value to the overall organization. This is usually accomplished by adapting a knowledge management model or cycle that continuously seeks feedback and improvements to the overall knowledge management process, which covers how knowledge should be created, validated, presented, distributed and applied.

Knowledge can also benefit the intellectual capital of an organization as described by Mousakhani and Rouzbehani (2014) who found in their research study that knowledge management has a significant relationship between intellectual assets and knowledge management practices.

Knowledge management technologies include the emergent Web 2.0 technologies, such as wikis and blog (Becerra-Fernandez \& Sabherwal, 2010). Such technologies have also supported the emergence of newer forms of knowledge models that utilize the collaborative nature of web technologies (Borjigen, 2015). In addition, other technologies that support knowledge management also include enterprise content management system, DSS, ERP, video conferencing, expert system. 


\section{KNOWLEDGe MANAGEMEnt Models AND CyCLES}

The study of knowledge management has led to the development of several models and cycles, which are briefly described in the following subsections. These models and cycles highlight important factors relevant to the case study analysis.

\section{A. Knowledge Management Models}

McAdam and McCreedy (1999) described three broad categories of knowledge management models, namely knowledge category models, intellectual capital models, and social constructed models. The following is a brief description of each:

\section{- Knowledge Category Models}

The aim of this type of models is to categorize knowledge into specific items or artifacts. Nonaka's Model, SECI, (Nonaka and Takeuchi, 1995), does so by distinguishing between tacit and explicit knowledge. Whereas other studies focused on other dimensions such as by McLoughlin and Thorpe (1993) looking at programmed knowledge and knowledge gained from questioning insight. Hedlund and Nonaka (1993) also had an expanded model that added additional dimensions of who is generating the knowledge.

In addition, Boisot (1987) also described a knowledge management model using the dimensions of codified knowledge and diffused knowledge. While the Karl Wiig knowledge management model (1993) aims to identify useful knowledge for organizations by organizing them into essential dimensions, such as completeness, connectedness, congruency, and perspective \& purpose.

The Choo Sense-Making Knowledge Management Model (1998) also focused on sense making, knowledge creation, and decision making skills, to use knowledge within a large framework in organizations. Snowden (2000) proposed the ASHEN model, which separates knowledge into five components, namely artefacts (i.e. documented items), skills, heuristics (cognitive thought process when making complex decisions), experience and natural abilities.

\section{- Intellectual Capital Models}

The aim of this type of models is to classify knowledge management as Human Capital (IC). For example, the Skandia IC model (Chase, 1997; and Roos and Roos, 1997), separated IC/ KM into human, customer, process and growth elements that are either related to human capital or organizational capital.

Another model proposed by Frid's (2003) aims to assess the level of maturity that an organization is at in relation to knowledge management. They range covers five levels starting with knowledge chaotic, then knowledge aware, then knowledge focused, then knowledge managed, and finally knowledge centric. This way an organization can determine how capable it is in delivering and improving its knowledge management capabilities.

\section{- Socially Constructed Models}

The aim of this type of model is to view knowledge as linked within the social and learning activities of organizations. One example, is the model proposed by Demerest's (1997) who adapted a previous model by Clark and Staunton's (1989) and integrated the elements of social interchange.

In addition, the model by Kogut and Zander (1992) also described knowledge as a source of competitive advantage for organizations. They focus on how knowledge is created and transferred within organizations.

The model by von Krogh and Roos Model (1995) also tries to distinguish between individual and social knowledge, with a focus on how people create and use knowledge in addition to how it is communicated and transferred between them.

While another model by Stankosky and Baldanza (2001) addresses various factors that enable knowledge management, such as leadership, organization structure, technology and learning in addition, to representing elements from other related disciplines, such as cognitive science, communication, individual and organizational behavior.

\section{B. Knowledge Management Cycles}

Birkinshaw and Sheehan (2002) highlighted in their study that all knowledge management lifecycle stages usually require a unique set of initiatives and technologies that are not specific to each organization. This indicates that each organization must go through a unique transformation process to be able to effectively manage knowledge, which usually requires effective processes, clear communication channels and measurable performance targets.

Knowledge management cycles are also closely related to organizational learning cycles, which are based on a decision execution cycle (M. W. McElroy, 2003). This usually involves planning, decision-making, monitoring, and evaluating the whole learning process and the generated knowledge.

A brief discussion about some of the key models commonly associated with knowledge management cycles is given below:

\section{- $\quad$ The Wiig KM Cycle}

This knowledge management cycle focuses on key elements that assist in:

- Collecting, analyzing and organizing knowledge.

- Storing such knowledge for later retrieval.

- Coordinating and retrieving required knowledge.

- Providing feedback on the utilization of knowledge and received benefits.

\section{- $\quad$ The Meyer and Zack KM Cycle}

This knowledge management cycle is derived from design and development of information products. Here, information is provided to stakeholders in various forms 
such as databases, news-feeds, or profiles. Key stages in this knowledge management cycle include:

$$
\begin{aligned}
& \text { - Acquire } \\
& \text { - Refine } \\
& \text { - Store } \\
& \text { - Distribute } \\
& \text { - Present }
\end{aligned}
$$

In addition, improvements and updates are important in this model through feedback.

\section{- $\quad$ The McElroy KM Cycle}

This knowledge management cycle focuses on knowledge production through formulating, codifying and evaluating a problem claim. The later part of the cycle focuses on knowledge integration, by broadcasting, searching, teaching, sharing knowledge.

This knowledge management cycle focuses on filtering generated knowledge to ensure that it is of benefit to the organization, which contrasts with traditional document management that stored everything.

\section{- $\quad$ The Bukowitz and Williams KM Cycle}

This knowledge management cycle focuses on the following key elements:

- The market-driven and tactical part that incorporates getting, using, learning, and contributing knowledge back enriching the knowledge-base.

- The knowledge assessment, building/sustaining and divesting of knowledge, and this is macroenvironment driven and strategic.

- The learning phase and a decision to either maintain or divest.

\section{EfFective Strategic KnOwledge Management}

Development of an effective strategic knowledge management requires a clear understanding of an organization's business strategy to be able to develop a comprehensive and aligned knowledge management strategy. This would ensure that knowledge management activities are geared towards the achievement of strategic objectives and the overall goal of achieving organizational excellence.

\section{A. Business Strategy}

Wiig since 1993, has called for practical and coherent frameworks for Knowledge Management stating that, managers have struggled with the absence of a framework that would help them to manage knowledge on a relevant and broad basis and to increase adoption of knowledge management practices and organizational resources dedicated. Even though, effective Knowledge Management grants many benefits for organizations and involved individuals (Cyr and Choo, 2010), there is no common method to benefit from an organization's knowledge capital.

In today's business environment, world-class enterprises have recognized the fact that managing their knowledge assets abilities and strategies are far more important than their ability or potentiality in investing in and managing their physical assets. Therefore, in this approach it is possible to examine the opportunity for the alignment between an organization's strategy and its knowledge management considering knowledge management as a strategic tool with potentiality of acquiring organizational objectives and competitive advantages in various aspects covering manpower training and development, maintaining lower costs and higher profits, and overall short term and long benefits. While per (Mathew, 2011), knowledge management provides benefits to organization by acting as crystal in developing and implementing organizational strategy. When knowledge management is implemented, companies can recognize how to exploit current resource to enjoy competitive advantages rivaling both internal and external competitors. Per (Beijerse, 1999) knowledge management is about harnessing the strategically driven needs of knowledge workers to continuously enhance their capabilities using available sources of information. This would assist in interpreting situations and creating knowledge insights based on experiences and skills gained in the learning process. Moreover, such knowledge creation cycles must be aligned with overall organizational goals to ensure that critical knowledge is identified and stored.

Organizations within existing knowledge management process are utterly supported by the expeditious development of information and communication technologies. knowledge management tools and techniques have greatly affected such organizations for the process conversion replacing tacit knowledge with explicit knowledge. Besides, they enabled capturing, sharing, dissemination and reuse of knowledge, and thus, this brought about reduction in process costs, participation of employees in knowledge development, knowledge management implementing as strategic tool, and holistic organizational development.

Too often, organizations implement cutting-edge technology and stumble upon the slowness to change in culture and behavior or to some extent resistance to change. In short, there would be insignificant improvement and progress in knowledge management capabilities regardless of what supporting system is used due to the interrelated organizational culture issues which affects employee's behavior around knowledge. Knowledge management is complex and multifaceted and demands an incorporation of various organizational components, namely, technology, HR practices, and organizational structure and culture for the benefit of ensuring that the right knowledge is made available on timely manner.

Ample examples of knowledge management systems are meant for boosting innovation, adaptability and responsiveness, however, they don't reach expectations. 
The reason is that only few executives know precisely what to do about knowledge management and how to mutate the entire knowledge management system.

\section{B. Associated Knowledge Management Strategy}

Developing an effective knowledge management strategy within an organization can be challenging without the support of comprehensive frameworks or methodologies. The following is a key framework supporting the development of knowledge management strategies that are essential to reaching organizational excellence.

\section{Accenture's Knowledge Management Framework}

For the interest of helping executives, Leigh Donoghue et al (1999) at the Accenture have constructed a framework associating specific Knowledge Management strategies to correspondingly specific challenges commonly facing organizations. Their knowledge management Framework assumes, which states that the aim is to understand how knowledge will be utilized first before trying to develop essential knowledge capabilities for an organization to succeed in their core processes and related activities ensuring organizational excellence (Donoghue et al., 1999). One illustration of this is in enriching the airline's supply-chain "know-how" as in catering service reducing supply cost and duration. Another example is in improving the airline's perception of what their guests prefer certain privileges, quality, or service; to assure success of its operations reaching organizational excellence and maintaining their competitive advantage over competition.

The initial step to applying the framework is to evaluate and categorize methods of performing work tasks. Here, the assessment is conducted on two perspectives, one is the interdependence level required, mean means to what degree are personnel required to collaborate and the second perspective regards the required work complexity and the degree to which personnel are committed to apply their judgments interpreting miscellaneous information needed for the job to be completed.

Using the two noted factors, researchers have categorized four different work models each corresponding to different type of work characteristics. The following are the four main models identified (figure 1):

- Integration Model, work in this model is often systematic, repetitively performed, relying on standard processes and approaches, while relays on close coordination between functions.

- Collaboration Model, work in this model incorporates improvisation and on-the-job training and practical learning, and depends upon deep expertise across functions and flexible teams' involvement.

- Expert Model, the work in this model requires judgment to solve unique problems and is strongly linked with key performers.

- Transaction Model, work in this model is commonly repetitive and does not require a lot of thought in it, as detailed procedures are in place for each step.

In principle, as there are different ways to performing the same process, there are no accurate connections between one core process and a corresponding work model, therefore, understanding how work is done would assist in categorizing the nature of the work and determine its proper knowledge management approach.

Substantially, each model exhibits its own discrete set of knowledge management challenges. For example, a key challenge in the collaboration model is in accomplishing leading-edge innovation. Towards taking over that challenge, an organization is obliged to motivate taking risk while joining the various knowledge domains, such as sales and distribution, and product $R \& D$, to consequently resolve all sophisticated issues related to knowledge management. On the contrary, organizations in the expert model usually need to concentrate on ensuring that its star performers are giving back outstanding results. To achieve that, a business must cope with problems such as hiring, retaining, and motivating talented personnel and overcoming information silo affect or the mentality causing it.

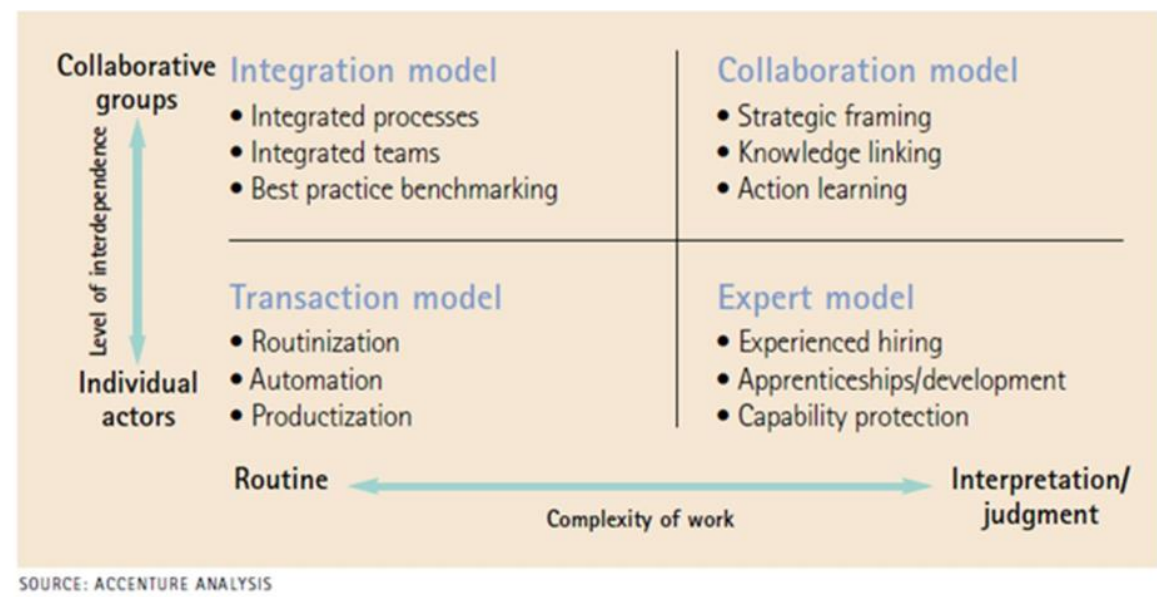

Fig.1. Potential KM strategies for each business model for tackling challenges (Donoghue, et al., 1999). 
The framework helps executives in gaining a better realization of their present knowledge management practices, besides identifying the knowledge management challenges associated with their core processes. The subsequent step to that diagnosis is a brief step of providing certain solutions to challenges since every group of challenges lead to several possible knowledge management strategies that are aligned with the overall organizational strategy for achieving organizational excellence.

A notable illustration of how to derive a knowledge management strategy from challenges is in the transaction model as most of its challenges evolve around the urgency of knowledge codification and consistent performance assurance. So, workable knowledge management strategies may contain automation for embedding standard operating procedures in systems, which is a form of structured knowledge, striving for standardizing employees' behavior by applying training programs. In integration model, we can see another illustration of this where coordinating activity across various parts of the organization is a challenge. Here, executives may contemplate standard processes or methodologies adoption because performance integration across multiple functions. For the expert model case, executives, may act by recruiting champions from other organizations, or choosing to place attention on internal training and development programs for champions to emerge though a long-term career planning process, including, mentoring and coaching programs (Donoghue et al., 1999).

Therefore, knowledge management should not focus on extracting knowledge from experts, but rather should focus on developing the experts in a continuous cycle that ensures knowledge creation and sharing is integrated into an organization's standard operating procedures and culture. In addition, knowledge management is also important for innovation and creativity to grow while keeping enough room for knowledge workers to test and pilot their discoveries with little fear of punishment by management for failures.

\section{CASE Study of SAudi Airline}

A case study approach has been used for this research, which utilized several data generation methods that included interviews and surveys. The in-depth interview was used with key personnel to obtain valuable insights into the use of strategic knowledge management to drive operational excellence. While the survey was conducted to assist in analyzing certain perspectives related to knowledge management within the organization. The sample was selected at random, with the main selection criteria for participants been that they work at the case study organization. About $85 \%$ participants responded to the questionnaire and the obtained data was used to further analyze the research study. The main aim of the survey was to:

- Identify the degree of knowledge management understanding within the organization's personnel
- Determine the importance of expected benefits and perceived values of knowledge management

- Determine the importance of knowledge management principles

- Determine the importance of linkages between principles and values of knowledge management

\section{A. Findings}

Saudi Airlines operates many offices and locations with thousands of employees in various technical and managerial jobs. This situation has presented a continuous challenge for the organization to sustain best practices and operational knowledge throughout its history. In addition, the organization has been going through a major transformation initiative that strives to improve its operational excellence and achieve their strategic goals by 2020. Therefore, to properly investigate Saudi Airlines as a case study a set of interviews with key personnel and a survey was utilized to obtain valuable insights into the use of strategic knowledge management to achieve operational excellence.

One of the main findings of this study was that Saudi Airlines as a large organization understands what knowledge management is, but at the same time it faces challenges in implementing it at a strategic and organizational levels. In addition, its key transformation initiatives have implemented a comprehensive project management office that is supported by a knowledgebase, which key stakeholders utilize for their decision making and progress monitoring. This has elevated the potential that knowledge can have to top management and has improved the value perceptions of how knowledge can contribute to an organization's achievement of its strategic goals.

Based on a set of interviews with key personnel within the organization the following are the key findings that were identified:

- Knowledge management tools and technologies are used at multiple levels to achieve various project-wise objectives; however, they fall short of achieving cross-functional and organization-level objectives.

- In terms of day-to-day operational knowledge management, this kind of knowledge is learnt from practice, experience, and the iterative process of performing daily tasks, there is no knowledge management system for storing and retrieving such kind of knowledge for the benefit of communicating knowledge to newcomers or other staff.

- Once new employees are hired, they are enrolled to an orientation period consisting of training programs for a period and later join a mentor who train them and provide them with the required knowledge to perform daily tasks. The reason is that the current Intranet portal is not configured to fulfill this role. 
- Although there are procedure documents for all systems and tasks that were provided by application vendors or compiled and updated by old-timers, there are all still all paper-based, organized into paper documents, and stored in office cabinets for individuals to seek for learning.

- The current Intranet portal is based on the web application platform of Microsoft SharePoint that is used to store some basic static information for each department or division, such as vision, mission, and objectives etc. In addition, it is used for downloading and printing some forms that are used for daily work, and more importantly it has some statistical reports, such as availability charts and reports that are made to keep managers updated on their department performance, these reports are updated regularly for certain time. The most used document sharing platform is simply sharing documents via the local network, intranet, as it is easily accessed and is based on simple file explorer interface with no odd GUI that may seem to be overwhelming when loading or looking for a certain hyperlinks or icons.

- A very effective example for knowledge management tools implemented in the case study organization is the recently adopted an internal social network that is based on Microsoft Yammer enterprise social networking service for private communication within organizations. Access to social network is governed by employees' corporate domain credentials, i.e. email addresses, so that only individuals within the organization may join and get access to it. In the social network, employees are updated with follow-ups on certain topics; moreover, they may discuss and contribute to topics by adding new ones or just liking and commenting on existing ones. Topics are based on various discussion groups such as the transformation project, crisis management, newspapers and the media, staff discounts, personal skills and talents, and the overall aviation news.

- Additionally, topics can be set to be viewed by all company staff, departmental or privately held between some members. Using the social network, employees may invite their coworkers engaging in real-time communications e.g. chatting, attaching and sharing files and documents.

- Since the social network launch, it has had tremendously evident results serving the knowledge management function in the organization. For instance, the recently launched campaign from the Sales Department asking all staff to participate in providing their suggestions to add ancillary revenue items for the newly added flight destination to the Maldives, there were many inputs from numerous staff brining about a crossdepartmental collaboration and competition where one employee won a prize for his best idea. Another example is an employee posting on the social network asking his peers about a certain work task and learning from them. Moreover, the organization often publicly publish corporate news letters or decrees about changes in the policies or regulations, one time an employee had some objections and so he commented about it, then the Director General was involved, took it seriously and positively amended the letter realizing the staff reasoning encouraging cross organizational collaboration.

The following are the main findings of the survey broken down into four key areas of knowledge management:

- Understanding of Knowledge Management by Organization Personnel

Table 1. Understanding of KM by Organization Personnel

\begin{tabular}{|l|l|l|l|l|l|}
\hline Question & Answer & \multicolumn{2}{|l|}{ Numbers } & \multicolumn{2}{|l|}{ Percentage } \\
\hline $\begin{array}{l}\text { Have you ever } \\
\text { heard } \\
\text { Knowledge } \\
\begin{array}{l}\text { Management } \\
\text { (KM)? }\end{array}\end{array}$ & Yes & 11 & 17 & $64.7 \%$ & $100 \%$ \\
\hline $\begin{array}{l}\text { Familiarity with } \\
\text { KM principles }\end{array}$ & No & 6 & & $35.3 \%$ & \\
\hline & Much & 4 & & $23.5 \%$ & \\
\hline & Somewhat & 4 & & $23.5 \%$ & \\
\hline & A Little & 4 & & $23.5 \%$ & \\
\hline & Very Little & 5 & & $29.5 \%$ & \\
\hline $\begin{array}{l}\text { Concept of effect } \\
\text { of Strategic KM } \\
\text { on } \\
\text { organizational } \\
\text { excellence }\end{array}$ & Very Much & 2 & 17 & $11.8 \%$ & $100 \%$ \\
\hline & Much & 3 & & $17.6 \%$ & \\
\hline & Somewhat & 9 & & $53.0 \%$ & \\
\hline & A Little & 0 & & $0 \%$ & \\
\hline & Very Little & 3 & & $17.6 \%$ & \\
\hline $\begin{array}{l}\text { Length } \\
\text { experience in in } \\
\text { using KM }\end{array}$ & Less than 1 & 9 & 17 & $53.0 \%$ & $100 \%$ \\
\hline & $1-3$ & 4 & & $23.5 \%$ & \\
\hline & $3-5$ & 3 & & $17.6 \%$ & \\
\hline & Above 5 & 1 & & $5.9 \%$ & \\
\hline
\end{tabular}

As highlighted in table 1 most respondents' opinion indicated that they are aware of knowledge management, with over two thirds indicating that they have heard of knowledge management. Their familiarity with knowledge management principles was varied ranging from $53 \%$ with little to very little familiarity and $47 \%$ who are much to somewhat familiar with the principles of knowledge management. This highlights the fact that based on the sample knowledge management is mostly a known concept in general terms however most indicate that they have limited understanding of it. On the other hand, $82.4 \%$ of respondents saw that the concept of strategic knowledge management has somewhat to very much effect on organizational excellence with only $17.6 \%$ seeing strategic knowledge management as having very little effect on organizational excellence. This supports the role that knowledge management tries to 
play within organizations as a catalyst for organizational excellence.

The length of experience in using knowledge management over half of the respondents, $53 \%$, had very little experience with less than one year, while a good portion, 41\%, had experience ranging between 1 to 5 years, with an exceptional case of more than that, $6 \%$. This highlights that fact that based on the respondent's answers most are aware of knowledge management but have limited years of experience in implementing it.

\section{- Values of Knowledge Management}

The questions of this section of the survey was used to analyze and compare the values of knowledge management using the mean and standard deviation as indicators of their significance to the survey participants. The result of this analysis is shown in table 2 .

Based on the respondents' answers the highest value identified for knowledge management was a mean of (4.1) for improved productivity of staff, then a mean of (3.9) for enhanced quality of delivered services, followed by a mean of (3.8) for improved satisfaction of customers and finally a mean of (3.6) for effective utilization of personnel. This provides an indication that respondents perceived knowledge management to be related more to human resource productivity and their output in the form of services delivered (refer to table 2 findings).

Table 2. Values of Knowledge Management

\begin{tabular}{|l|l|l|}
\hline Question Mean & Standard Deviation \\
\hline $\begin{array}{l}\text { Improved satisfaction of } \\
\text { Customers }\end{array}$ & 3.8235 & 0.6169 \\
\hline $\begin{array}{l}\text { Improved productivity of } \\
\text { staff }\end{array}$ & 4.0588 & 0.6389 \\
\hline $\begin{array}{l}\text { Enhanced quality of } \\
\text { delivered services }\end{array}$ & 3.8824 & 0.8318 \\
\hline $\begin{array}{l}\text { Effective Utilization of } \\
\text { Personnel }\end{array}$ & 3.5882 & 1.1910 \\
\hline
\end{tabular}

\section{- Implemented Knowledge Management Principles}

The questions of this section of the survey was used to analyze and compare the implemented knowledge management principles using the mean and standard deviation as indicators of their significance to the survey participants. The result of this analysis is shown in table 3.

In reviewing the findings of respondents' answer to the implemented knowledge management principles, the highest identified principles were knowledge documentation with a mean of (3.6) and knowledge communication \& collaboration with a mean of (3.6). On the other hand, other principles relating to how knowledge management is implemented and benefiting the organization was viewed as less critical (refer to table 3 findings).
Table 3. Implemented Knowledge Management Principles

\begin{tabular}{|l|l|l|}
\hline Question & Mean & Standard Deviation \\
\hline $\begin{array}{l}\text { Alignment of KM to } \\
\text { Business }\end{array}$ & 3.5294 & 0.7759 \\
\hline $\begin{array}{l}\text { Knowledge } \\
\text { Communication } \\
\text { Collaboration }\end{array}$ & 3.5882 & 0.8442 \\
\hline $\begin{array}{l}\text { Knowledge } \\
\text { Documentation }\end{array}$ & 3.6471 & 0.6809 \\
\hline $\begin{array}{l}\text { Knowledge Management } \\
\text { Lifecycle }\end{array}$ & 3.4706 & 0.6056 \\
\hline
\end{tabular}

- $\quad$ Link between Implemented Knowledge Management Principles and Values

The questions of this section of the survey was used to analyze and compare the links between the implemented knowledge management principles and values using the mean and standard deviation as indicators of their significance to the survey participants. The result of this analysis is shown in table 4.

In reviewing the findings of the link between knowledge management principles and values, improved employee engagement with a mean of (3.9) was indicated as the highest benefit from such a link. On the other hand, organizational excellence achievement with a mean of (3.7) and improved organizational cultural with a mean of (3.7) were also indicated as important benefits from such a link (refer to table 4 findings).

Table 4. Link between Implemented Knowledge Management Principles and Values

\begin{tabular}{|l|l|l|}
\hline Question & Mean & Standard Deviation \\
\hline $\begin{array}{l}\text { KM receives support } \\
\text { from the top } \\
\text { management }\end{array}$ & 3.529411765 & 0.977249866 \\
\hline $\begin{array}{l}\text { Organizational } \\
\text { Excellence } \\
\text { Achievement }\end{array}$ & 3.705882353 & 0.955769224 \\
\hline $\begin{array}{l}\text { Strategic Knowledge } \\
\text { Management } \\
\text { Attainment }\end{array}$ & 3.470588235 & 1.03569511 \\
\hline $\begin{array}{l}\text { Improved Employee } \\
\text { Engagement }\end{array}$ & 3.882352941 & 0.75788816 \\
\hline $\begin{array}{l}\text { Improved } \\
\text { Organizational Culture }\end{array}$ & 3.705882353 & 0.892102993 \\
\hline
\end{tabular}

\section{ANALYSIS \& DISCUSSION}

Based on the findings of both the interviews and survey, strategic knowledge management is well-known as a concept and is perceived as an enabler for achieving organizational excellence. However, such realization of the benefits of SKM was mostly stated and narrowly implemented at the project management level rather than in the day-to-day operations of Saudi Airlines, this is mainly due to top management focus on achieving their comprehensive organizational transformation program. 
At the same time, most indicated that they have limited experience in managing knowledge and that no clear methodology is adapted. However, knowledge is managed within the various projects as a key resource for success. This leads us to deduce that SKM must be implemented at an organizational level for it to drive organizational excellence.

On the other hand, it is important to highlight that even though Saudi Airlines does not implement a comprehensive SKM strategy its main principles or values can still be found within their corporate strategy and SBU plans. Therefore, we can deduce that SKM needs to be championed within an organization to obtain its required level of support and be identified as a clear driver for organization excellence, otherwise it would still benefit the organization but at a much lower level. This is further supported by the findings that most view SKM as benefiting staff productivity followed by the quality of their output. In addition, most also perceive that knowledge documentation, communication and collaboration to be the most important principles of SKM, which again supports the need for SKM to be in place for both explicit and tacit knowledge types.

In addition, Saudi Airlines has not utilized knowledge as a strategic resource with its external partners to strengthen their relationship and effectiveness. This area was researched recently in a study by Al-mutairi and Qureshi (2014), who proposed a framework for KMS strategic alliance. With such a concept in place corporate processes would be supported from start to finish by a comprehensive knowledge management system targeting both internal employees and external partners.

Another important finding was that improving employee engagement and organizational culture were among the top benefits of linking knowledge management principles with expected benefits within an organization's strategy. This is an important point as SKM supports both these areas by supporting the full lifecycle of tacit knowledge and supporting knowledge communication and collaboration.

In addition, Saudi Airlines does not adapt a clear organizational excellence model to be used to assess their levels of excellence, but rather depend on a customized performance measurement system to track and monitor their strategic objectives. Therefore, the implementation of SKM in such scenarios will require clear links to these objectives and performance measure, in addition to identify the contribution that knowledge provides to the organization's strategic critical success factors.

Thus, implementing SKM successfully requires a clear link between it and the main elements of organizational excellence such as leadership, people, strategy and process, just to name a few examples. These elements can either be adapted from the organization's strategy or adapted from an international organizational excellence model.

\section{SKM IMPLEMENTATION FRAMEWORK}

The lack of a clear linkage between organizational excellence elements or strategic objectives with knowledge management components may lead to unsuccessful or limited implementation of strategic knowledge management. Therefore, the proposed framework, as highlighted in figure 2, aims to introduce the key components needed for a comprehensive and integrated implementation of SKM in an organization looking to achieving organizational excellence.

The framework is divided into three main layers, namely organizational performance, knowledge communication \& collaboration, and knowledge management processes \& data. Organization performance deals with identification of performance targets within a clear dashboard that is driven by strategic objectives and critical success factors, in addition to, the input from both external and internal business and knowledge management environment analysis. This layer must be done at a strategic level with top management to be able to correctly identify and link all objectives and organizational excellence elements with knowledge management components.

On the other hand, the knowledge communication \& collaboration layer deals with increasing employee engagement levels required for an effective knowledge driven organization culture to prosper and grow using enterprise social network. This layer would focus on the organizational culture elements that supports knowledge management, while utilizing enterprise social networking platforms to support the communication and collaboration of knowledge. In addition, this layer would support the exchange of tacit knowledge in an interactive manner between organization personnel.

At the last layer, knowledge management processes \& data deals with the underlying portfolio of systems, applications and infrastructure needed to deliver organizational excellence with knowledge management. These knowledge management tools and systems base their benefit from identifying both the value creating processes and high value-adding knowledge artefacts. This layer utilizes business process management systems to enable the automation of knowledge management cycles and distribution of high-value adding knowledge.

With these layers in place organization personnel should be able to link their knowledge management activities with strategic objectives. In addition, they would also avoid unproductive knowledge management activities that do not directly achieve results.

Therefore, organizational personnel would be supported with effective knowledge management processes to streamline their knowledge cycles, interactive employee engagement programs to build the needed awareness and culture, and comprehensive performance measurement systems to track the achievement of organizational excellence. 
The proposed framework is based on the outcome of the findings and the analysis of this research study. However, due to the lack of time it is not comprehensively evaluated and we propose to evaluate this framework in our future work.

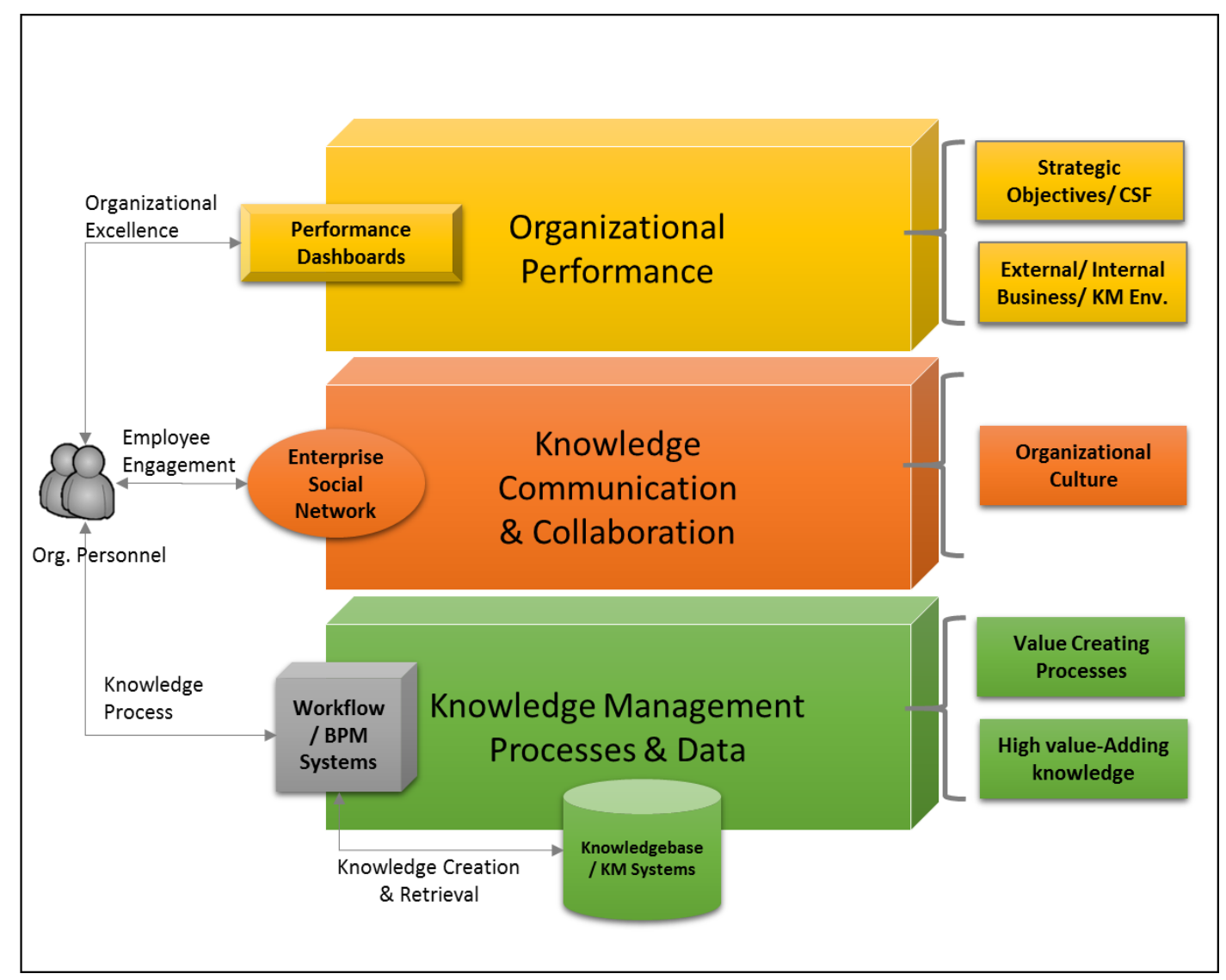

Fig.2. SKM implementation Framework

\section{CONCLUSIONS}

In this research paper, we presented a case study of Saudi Airlines, which included a set of interviews and a questionnaire based survey, to investigate the potential effects the strategic knowledge management may have on achieving organizational excellence.

The main findings have indicated that knowledge management as a concept maybe well perceived by many individuals as a general term, however its technical or practical implementation in a real-world scenario is not well-understood. Many see it as a general goal that people should strive to achieve but they usually fall short in defining clear strategies and plans on how to achieve knowledge management goals.

In addition, the findings supported that large organizations are faced with the challenge of using expert knowledge of its personnel who are not physically available to interact with and exchange their knowledge with others due to the size of the organization.

One clear finding from the research study was how emerging enterprise social network systems have played a major role in institutionalizing collaboration and corporate socializing within the organization. These factors also play an important role in improving overall employee satisfaction of their work environments, which was recently research by Kianto Vanhala and Heilmann (2016) who indicated that the sharing of intra organizational knowledge has a direct link with employee satisfaction in organizations who utilize streamlined knowledge management systems.

These technologies if properly implemented can increase the successful implementation of SKM.

To bridge the gap between strategic objectives and critical success factors with the tacit and explicit elements of knowledge management a framework has been proposed to assist in implementing SKM within an organization. This would allow SKM to clearly support organizations in improving their technological innovations and competitive advantages (Lee, et al., 2016).

This research study was limited to one organization. Thus, it may include varying degrees of bias in the responses or opinions obtained. In addition, due to the lack of time available for this research study the proposed framework was not evaluated, however we expect to conduct this evaluation in future work.

Additional future work can potentially cover exploring if centers of excellence, or enterprise social networking have value in strategic knowledge management and 
overall organizational excellence. Target organizations can setup centers of excellence in knowledge management, which acts as a focal point for knowledge creation and distribution. This center of excellence would utilize organizational networks to reach all corners of the organization in search of valuable knowledge.

\section{REFERENCES}

[1] Alberto Carneiro, (2000). How does knowledge management influence innovation and competitiveness. Journal of Knowledge Management, 4(2), 87 - 98.

[2] Al-mutairi, S. B., \& Qureshi, M. R. J. (2014). A Novel framework for Strategic Alliance of Knowledge Management Systemsf. International Journal of Modern Education and Computer Science, 6(4), 38.

[3] Argote, L. and Ingram, P. (2000). Knowledge transfer: A basis for competitive advantage in firms. Organizational Behavior and Human Decision Processes, 82(1), 150-169.

[4] ASQ (2016) What Is Organizational Excellence? [Online]. Available from: http://asq.org/learn-aboutquality/organizational-excellence/ (Accessed: 6 April 2016)

[5] Becerra-Fernandez, I. and Sabherwal, R. (2010). Knowledge Management: Systems and Processes. Armonk (N.Y.); London: M.E. Sharpe.

[6] Beijerse, R. P. (1999). Questions in knowledge management: defining and conceptualizing a phenomenon. Journal of Knowledge Management, 3(2), 94-109.

[7] Bhatt, G. D. (2001). Knowledge management in organizations: examining the interaction between technologies, techniques, and people. Journal of knowledge management, 5(1), 68-75.

[8] Boisot, M. (1987) Information and Organizations: The Manager as Anthropologist, Fontana/Collins, London

[9] Boisot, M. (1998) Knowledge assets: Securing competitive advantage in the information economy, New York: Oxford University Press.

[10] Borjigen, C. (2015). Mass collaborative knowledge management: Towards the next generation of knowledge management studies. Program, 49(3), 325-342.

[11] Bukowitz, W., \& Williams, R. (2000). The knowledge management field book. London: Prentice Hall.

[12] Cyr, S., \& Choo, C. W. (2010). The individual and social dynamics of knowledge sharing: An exploratory study. Journal of Documentation, 66(6), 824 - 846.

[13] Dalkir, K. (2013). Knowledge management in theory and practice. Routledge.

[14] Donoghue, L. P., Harris, J. G., and Weitzman, B. A. (1999). Knowledge management strategies that create value. Outlook, 1(1), 48-53.

[15] Earl, M. J. (1997) 'Knowledge as strategy: Reflections on Skandia International and Shorko Films', in Prusak L. (ed.) Knowledge in organizations, Boston, MA: ButterworthHeinemann.

[16] Evans, M. M. and Ali, N. (2013) 'Bridging knowledge management life cycle theory and practice', International Conference on Intellectual Capital, Knowledge Management and Organisational Learning ICICKM 2013 - Conference Proceedings, Washington, DC: Academic Conferences and Publishing International, pp. 156-165.

[17] Harrington, H. J. (2006) The Five Pillars of Organizational Excellence [Online]. Quality Digest. Available from: http://www.qualitydigest.com/aug06/articles/05_article.sh tml (Accessed: 6 April 2016)
[18] Heisig, P. (2009). Harmonisation of Knowledge Management - Comparing $160 \mathrm{KM}$ frameworks Around the Globe. Journal of Knowledge Management. 13(4), 431.

[19] Heisig, P., Heisig, P., Suraj, O. A., Suraj, O. A., Kianto, A., Kianto, A., ... \& Fathi Easa, N. (2016). Knowledge management and business performance: global experts' views on future research needs. Journal of Knowledge Management, 20(6), 1169-1198.

[20] Kianto, A., Vanhala, M., \& Heilmann, P. (2016). The impact of knowledge management on job satisfaction. Journal of Knowledge Management, 20(4), 621-636.

[21] Lee, V. H., Foo, A. T. L., Leong, L. Y., \& Ooi, K. B. (2016). Can competitive advantage be achieved through knowledge management? A case study on SMEs. Expert Systems with Applications, 65, 136-151.

[22] Martensson, M. (2000). A critical review of knowledge management as a management tool. Journal of Knowledge Management, 4(3), $204-216$.

[23] Mathew, Viju. (2011) "KM Strategies (Part 2): Change and Development." Journal of Knowledge Management Practice 12, no. 2

[24] McAdam, R., \& McCreedy, S. (1999). A critical review of knowledge management models. The learning organization, 6(3), 91-101.

[25] McElroy, M. (1999, April). The knowledge life cycle. In Proceedings of the ICM Conference on KM. Miami, FL.

[26] McElroy, M. W. (2003). The new knowledge management: complexity, learning, and sustainable innovation. KMCI Press.

[27] Meyer, M., \& Zack, M. (1996). The design and implementation of information products. Sloan Management Review, 37 (3), 43-59.

[28] Mousakhani, M., and Rouzbehani, K. (2014). On Knowledge Management: Intellectual Assets as Facilitating Infrastructure. International Journal of Asian Business and Information Management (IJABIM), 5(4), 23-33.

[29] Ringrose, D. (2013). Development of an organizational excellence framework. The TQM Journal, 25(4), 441-452.

[30] Wiig, K. (1993). Knowledge management foundations. Arlington, TX: Schema Press.

\section{Authors' Profiles}

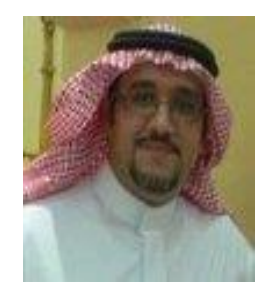

Osama S. Islam graduated from King Saud University in Riyadh, Saudi Arabia in 1998 with a B.Sc. in computer \& information sciences - information systems. He has worked over 19 years as an information technology and management consultant with a range of experience in information systems, organizational development, business technology solutions, and strategic management consulting. His experience in consulting companies covers a wide range of industries; such as contracting, manufacturing, retail, tourism, banking, healthcare and public sector organizations.

He is currently holding the position of General Manager in an information technology company in Saudi Arabia. He is also currently pursuing a Master's degree in computer information systems at the King Abdulaziz University in Jeddah, Saudi Arabia. 


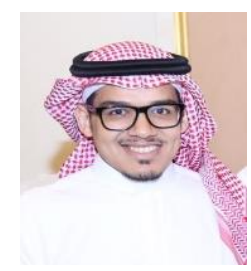

Mohammed Ashi. is currently working toward the Master's degree in Computer Information Systems at the King Abdulaziz University in Jeddah, Kingdom of Saudi Arabia. He is focusing on aspectlevel sentiment analysis and its various applications for the Arabic language. Other topics of interest include Natural language processing (NLP) being a sub-field of computer science, artificial intelligence (AI) and computational linguistics.

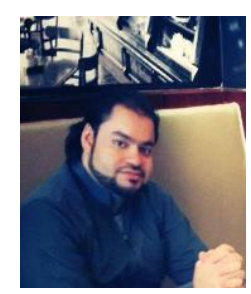

Fahad Masood Reda studied at King Abdulaziz University in the College of Economics and Administration in major of Management Information systems, and then worked as an I.C.T Teacher in Thamer International School for three years, and now he is pursuing his Master's Degree in major of Computer Information system in Computing and Information Technology College at King Abdulaziz University.

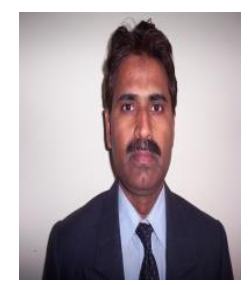

Dr. Aasim Zafar is presently working as Associate Professor in the Department of Computer Science, Aligarh Muslim University, Aligarh, India. He worked as Assistant Professor in Information Systems Department, Faculty of Computing and Information Technology, King Abdulaziz University, Jeddah, Saudi Arabia from 2011-2016. In research, his current interests include Adaptive elearning, Mobile learning, Virtual Learning Environments, Information Retrieval and Mobile Ad hoc Networks. He has a number of research publications to his credit. Dr. Zafar is member of Internet Society (ISOC).

How to cite this paper: Osama S. Islam, Mohammed Ashi, Fahad M. Reda, Aasim Zafar,"Strategic Knowledge Management as a Driver for Organizational Excellence: A Case Study of Saudi Airlines", International Journal of Modern Education and Computer Science(IJMECS), Vol.9, No.7, pp.38-49, 2017.DOI: 10.5815/ijmecs.2017.07.05 